\title{
Pembagian jaringan komputer menggunakan virtual local area network guna mendukung perpustakaan digital
}

\author{
Hero Wintolo ${ }^{1}$, Amalia Farhati ${ }^{2}$ \\ 1,2Perpustakaan Sekolah Tinggi Teknologi Adisutjipto Yogyakarta \\ Jl. Janti, Blok-R, Lanud Adisutjipto, Banguntapan, Bantul, Daerah Istimewa Yogyakarta, 55198 \\ E-mail:1'herowintolo@stta.ac.id,2amalia@stta.ac.id
}

Received: December 2019; Accepted: September 2020; Published: December 2020

\begin{abstract}
Digital libraries have been widely applied in educational institutions in Indonesia as a complement conventional libraries. The purpose of this research is to know division computer network access at the Adisutjipto Intitute of Technology (STTA) library. The research method used is a qualitative method using Prepare Plan Design Implement Operate and Optimize (PPDIOO). The result research is that people who have internet access will not be able to enter the digital library network. Computer network users who want to access digital libraries must log into the computer network that provides digital books in the library using a Virtual Local Area Network (VLAN). Making this VLAN requires a computer network infrastructure in the form of a Local Area Network (LAN) and computer network equipment in the form of a switch that can be used to configure multiple VLANs in a LAN. Some of the existing services in the library are placed on one VLAN and the digital library is placed on another VLAN. From the test results, it can be seen that between computers that provide services in the library on VLAN 2 cannot communicate via the connecting network to VLAN 1 where the digital library with website based services will be located. This is evidenced by the ping command which generates request time out information. VLANs network in the STTA library have been able to provide support for plans to improve services to members and academicians in the form of a digital library.
\end{abstract}

Keywords: Computer network access; VLAN; Digital library

\begin{abstract}
Abstrak
Perpustakaan digital sudah banyak diterapkan pada institusi pendidikan di Indonesia sebagai pelengkap perpustakaan konvensional. Tujuan penelitian ialah mengetahui pembagian akses jaringan komputer pada Perpustakaan Sekolah Tinggi Teknologi Adisutjipto (STTA). Metode penelitian menggunakan metode kualitatif melalui Prepare Plan Design Implement Operate and Optimize (PPDIOO). Hasil penelitian menunjukkan bahwa orang yang memiliki akses internet tidak mudah masuk ke dalam jaringan perpustakaan digital. Pengguna jaringan komputer yang ingin mengakses perpustakaan digital harus masuk ke dalam jaringan komputer yang menyediakan buku digital pada perpustakaan menggunakan Virtual Local Area Network (VLAN). Pembuatan VLAN ini membutuhkan sebuah infrastruktur jaringan komputer dalam bentuk Local Area Network (LAN) serta adanya peralatan jaringan komputer berupa switch yang dapat digunakan untuk konfigurasi beberapa VLAN dalam LAN. Beberapa layanan yang ada di perpustakaan diletakkan pada satu VLAN dan perpustakaan digital diletakkan pada VLAN lainnya. Sesuai hasil pengujian terlihat bahwa antar komputer yang menyediakan layanan di perpustakaan pada VLAN 2 untuk tidak dapat berkomunikasi melalui jaringan penghubung ke VLAN 1 tempat perpustakaan digital layanan berbasis website yang nantinya diletakkan. Hal ini dibuktikan dengan perintah ping yang menghasilkan informasi request time out. Jaringan VLAN di Perpustakaan STTA telah mampu memberikan dukungan pada rencana peningkatan layanan pada anggota dan sivitas akademika dalam bentuk perpustakaan digital.
\end{abstract}

Kata Kunci: Akses jaringan komputer; VLAN; Perpustakaan digital 


\section{PENDAHULUAN}

Perpustakaan Sekolah Tinggi Teknologi Adisutjipto (STTA) merupakan Unit Pelayanan Teknis (UPT) yang menjadi bagian layanan akademis bagi segenap sivitas akademika STTA, baik dosen, karyawan, serta mahasiswa aktif STTA, dalam hal peminjaman dan pengembalian koleksi buku cetak. Layanan yang diberikan hampir sama dengan perpustakaan di tempat lain, yaitu memberikan layanan baca serta pinjam kembali buku cetak koleksi yang dimiliki, layanan pengadaan buku cetak untuk penambahan koleksi, layanan perbaikan, dan penghapusan koleksi buku cetak dan majalah yang mengalami kerusakan.

Buku cetak di perpustakaan STTA, antara lain buku teks untuk mendukung perkuliahan, buku panduan dan teknik penyelesain permasalahan, majalah, jurnal nasional dan internasional, serta buku bacaan lain yang dapat menarik minat mahasiswa untuk mengunjungi perpustakaan. Perpustakaan STTA pun menyediakan layanan akses jurnal elektronik yang berbayar. Artikel pada jurnal berbayar tidak memiliki versi cetak dan hanya dapat diakses melalui komputer yang tersambung ke internet menggunakan mekanisme login di sebuah akun dengan username dan password yang harus dimasukan pustakawan dalam mengaksesnya.

Teknologi informasi telah membantu kegiatan sirkulasi perpustakaan, seperti, proses membaca, peminjaman, dan pengembalian buku yang awalnya konvensional ke katalog elektronik. Selain itu, teknologi informasi di perpustakaan pun telah membantu meringankan tugas pustakawan dalam memberikan pelayanan sirkulasi yang awalnya total dilakukan pustakawan. Setelah berkembangnya teknologi informasi, pustakawan hanya melayani pencatatan berbasis komputer dalam peminjaman dan pengembalian. Maka, anggota perpustakaan pun belajar mandiri dalam melakukan kegiatan pencarian dan sirkulasi buku cetak.

Anggota perpustakaan merupakan sivitas akademika STTA yang melakukan kegiatan pencarian informasi melalui katalog elektronik sebagai media pencarian koleksi. Informasi yang dicari biasanya judul buku, pengarang, penerbit, dan letak buku di rak yang tersedia. Dengan demikian, anggota perpustakaan akan mengetahui kondisi dan keberadaan buku yang dicari hingga menemukannya di rak yang bersangkutan. Anggota perpustakaan dapat membaca buku yang telah ditemukan di ruang baca perpustakaan dan jika anggota perpustakaan ingin meminjamnya harus menggunakan kartu anggota perpustakaan. Sesuai hal ini, teknologi informasi telah memudahkan mekanisme kegiatan sirkulasi, seperti peminjaman dan pengembalian buku yang dilakukan dengan cepat dan direkam dengan baik.

Selain itu, teknologi informasi di perpustakaan tidak hanya digunakan untuk pelayanan sirkulasi saja melalui perangkat lunak Senayan Library Management System (SLiMS) namun dapat juga dilakukan dalam layanan referensi (Putra \& Irawati, 2018). Perangkat lunak SLiMS merupakan sebuah perangkat lunak (software) untuk pengelolaan perpustakaan yang awalnya konvensional. Perangkat lunak ini dapat digunakan secara gratis atau tidak berbayar dan sudah terbukti membantu pustakawan dalam memberikan pelayanan peminjaman dan pengembalian buku cetak di perpustakaan STTA. Namun, Perpustakaan STTA belum 
memiliki perangkat lunak dalam melayankan baca buku digital. Maka peneliti melalui penelitian merancang proses pembuatan perpustakaan digital yang diawali dengan menyiapkan infrastruktur jaringan komputer sebagai pendukung utama perpustakaan digital.

Beberapa kampus memang sudah memberikan pelayanan baca buku digital melalui beberapa ketentuan yang berlaku, misalnya pada Fakultas Kedokteran Universitas Gadjah Mada yang memberikan layanan unduh dan cetak buku digital menggunakan jaringan intranet (Sukirno, 2015). Perpustakaan di Fakultas Kedokteran menggunakan jaringan intranet untuk membatasi jangkauan akses dari peralatan komputer dalam mengakses koleksi buku digital ini, misalnya dari pengunjung luar lembaga.

Jaringan intranet merupakan jaringan internet dalam skala Local Area Network (LAN). Secara fisik, jaringan ini merupakan LAN dengan perangkat lunak yang digunakan untuk mengatur dan mengendalikan jaringan internet. Layanan perpustakaan digital dalam bentuk koleksi digital yang dilayankan secara terbuka (open library) berfungsi sebagai media penelusuran informasi dan mempermudah transaksi yang dapat ditemukan juga di Perpustakaan Telkom University (Oktaviani, Yusup, \& Khadijah, 2018). Perpustakaan Telkom University memiliki pelayanan perpustakaan yang memudahkan sivitas akademika dalam melakukan pencarian, pemesanan, dan peminjaman buku cetak. Selain itu, perpustakaan ini pun memudahkan anggota perpustakaan dalam membaca dokumen digital lainnya, seperti tugas akhir dalam bentuk digital. Perpustakaan memberikan kebebasan akses hanya bagi anggota perpustakaan saja. Hal ini dilakukan untuk menghindari pengunduhan dokumen ilegal.

Selain itu, perpustakaan lain yang menyediakan pelayanan membaca koleksi digital dilakukan di Universitas Atmajaya Yogyakarta (Dana, Samosir, \& Widiyasa, 2015). Perpustakaan ini menyediakan pelayanan perpustakaan yang didukung teknologi informasi dalam LAN yang diharapkan dapat menghubungkan semua komputer di kampus tersebut sehingga akses perpustakaan digital dapat dilakukan jarak jauh tanpa harus berkunjung secara fisik ke perpustakaan.

Lokasi gedung kampus yang jaraknya berdekatan memudahkan penggunaan LAN sebagai pendukung infrastruktur perpustakaan digital. Akan tetapi, ada beberapa kampus yang lokasi gedung cukup jauh dan dukungan infrastruktur LAN tidak mencukupi dikarenakan teknologi LAN memiliki keterbatasan jarak jangkauan antara satu komputer dengan komputer lain. Untuk itu, dibutuhkan peralatan jaringan komputer, berupa modem, router, dan koneksi jaringan internet untuk menyatukan LAN yang terpisah akibat jarak yang jauh agar dapat saling terhubung. Walaupun demikian, hal ini dapat menimbulkan celah keamanan pada sistem informasi perpustakaan digital dari serangan hacker.

Sistem informasi perpustakaan digital yang dirancang dan dibuat khusus perguruan tinggi tersebut lebih mudah untuk dikembangkan dibandingkan perpustakaan yang menggunakan sistem yang tidak berbayar (open source). Perpustakaan dapat melakukan inovasi dalam sistem LAN yang digunakan. Hal ini berbeda dengan layanan open source yang tampilan dan sistem layanannya tidak bisa diubah oleh perpustakaan karena terkait lisensi. Walaupun begitu, 
layanan open source dalam proses unduh koleksi digital dapat mengendalikan akses koleksi sehingga tidak melanggar peraturan dan perundangan yang berlaku.

Pelayanan perpustakaan digital telah memberikan manfaat bagi perkembangan koleksi, namun ada beberapa kampus yang mengalami kendala ketika proses pelayanan perpustakaan digital, contohnya keterbatasan pengetahuan Sumber Daya Manusia (SDM) perpustakaan tentang perangkat lunak (software) yang akan digunakan dan rasa ketergantungan pada staf Teknologi Informasi (TI) (Irkhamiyati, 2017). Pustakawan sebagai SDM yang mengelola perpustakaan awalnya memiliki kemampuan pengelolaan dan manajemen perpustakaan secara konvensional konvensional. Maka, pustakawan pun ditantang harus memiliki keahlian dalam mengoperasikan perangkat lunak (software) perpustakaan digital. Bagi pustakawan yang belum berhasil mengoperasikan perangkat lunak (software), maka mereka meminta bantuan staf TI. Apabila staf TI sedang tidak bisa membantu pustakawan, maka layanan perpustakaan digital pun terhambat.

Beberapa perguruan tinggi dalam peningkatan SDM pustakawan telah memberikan pelatihan pengoperasian perangkat lunak (software) yang digunakan sebagai layanan perpustakaan digital, antara lain EPrints, yang bersifat open source seperti halnya SLiMS yang menyimpan metadata koleksi perpustakaan. Namun EPrints memiliki fungsi untuk menampung data dan koleksi digital yang digunakan sivitas akademika dari perguruan tinggi yang menggunakannya.

Perangkat lunak EPrints memuat koleksi digital yang dapat dilakukan konfigurasi sebagai dokumen umum dan khusus. Dokumen yang bersifat umum memiliki arti bahwa pengguna untuk membaca dan mengunduh koleksi digital tidak perlu login ke sistem. Pengguna yang belum terdaftar anggota perpustakaan digital pun dapat membaca dan mengunduh dokumen dalam EPrints. Adapun dokumen yang bersifat khusus memiliki arti bahwa pengguna dapat membaca dan mengunduh dokumen di EPrints jika sudah terdaftar, memiliki akun, dan login dalam sistem menggunakan username dan password yang didapatkan saat mendaftarkan diri. Walaupun demikian, pengguna yang sudah terdaftar atau belum dapat melakukan proses unduh dokumen sehingga EPrints sangat rawan terhadap pelanggaran Hak Cipta (HAKI) koleksi digital yang ada.

Perangkat lunak (software)) yang digunakan dalam memberikan pelayanan perpustakaan digital berbeda dengan pelayanan pada perangkat lunak (software) SLiMS. Pada perpustakaan digital, perangkat lunak yang digunakan harus mampu untuk mencari dan membuka buku yang tersedia pada layanan tersebut. Kemampuan ini didukung melalui tampilan antara muka serta fungsionalitas yang baik pada perangkat lunak (software) yang digunakan.

Dengan demikian, pelayanan EPrints di perpustakaan digital perlu diujikan kembali untuk mengetahui efisiensi secara internal, mengetahui kemampuan perangkat lunak (software) dalam melakukan interaksi, dan efektivitas seperti yang telah diujikan di Magister Management Digital Library (MMDTGILIB) UGM (Sugianti, 2016). Pengujian terhadap perangkat lunak yang digunakan perpustakaan dalam 
memberikan pelayanan perpustakaan digital sudah dilakukan walaupun tidak menggunakan standar pengujian tampilan dan fungsi pada sistem informasi dengan menggunakan white box atau black box. Sesuai hasil pengujian Sugianti (2016), responden rata-rata memberikan nilai baik sejumlah 81. Semakin banyak jumlah responden mengisi kuesioner dan memberikan penilaian terhadap perangkat lunak perpustakaan maka hasilnya akan semakin valid.

Suatu lembaga membangun perpustakaan digital tidaklah mudah. Perpustakaan harus menyediakan perangkat lunak (software) yang mampu mengintegrasikan keberadaan perpustakaan konvensional, bukan meniadakannya. Maka, perpustakaan pun harus memiliki SDM yang mempuni dalam bidang teknologi informasi.

Pembangunan perpustakaan digital memerlukan tiga kata kunci yang harus dipersiapkan, di antaranya integrasi, keterkaitan, dan kerja sama (Rodliyah, 2012). Perpustakaan digital harus memiliki integrasi dan keterkaitan yang dilandasi sistem menuju akses secara luas dengan jarak jangkauan yang tidak terbatas. Hal ini hanya dapat dilakukan perpustakaan menggunakan jaringan internet. Perpustakaan menekankan kerja sama untuk mengupayakan sumber koleksi digital dapat digunakan bersama atas dasar kesepakatan. Maka, kerja sama ini harus dilakukan terlebih dahulu agar tidak terjadi tumpang tindih antara hak, kewajiban, dan wewenang antar pihak yang melakukan kerja sama.

Hasil kesepakatan dalam kerja sama dapat digunakan sebagai landasan hukum dalam melakukan integrasi data. Selain itu, perpustakaan pun dalam koleksi digital menggunakan jaringan internet yang tertutup agar proses membaca dan mengunduh koleksi digital tidak melanggar peraturan dan perundangundangan yang ada. Adapun biaya untuk menghubungkan antar perpustakaan digital yang aman tidaklah murah. Salah satu produk yang biasanya digunakan untuk menghubungkan jaringan antar perpustakaan menggunakan Virtual Private Network (VPN), sebagai salah satu produk perusahaan penyedia jasa layanan koneksi internet. Namun, peserta kerja sama yang memiliki sumber daya keuangan yang terbatas masih terkendala besaran biaya layanan VPN sehingga penghambat kegiatan integrasi jaringan.

Adapun hambatan lain dalam membangun perpustakaan digital ialah perpustakaan harus menyesuaikan diri dengan peraturan dan perundangundangan yang berlaku. Hal ini terkait koleksi digital, misalnya buku sebagai objek dari Hak Kekayaan Intelektual (HAKI) seseorang yang perlindungannya diatur dalam perundang-undangan (Kusmawan, 2014). Undang-Undang HAKI sendiri mengalami perjalanan sangat panjang yang dimulai pada 1982 hingga mengalami amandemen, perbaikan, dan memunculkan UndangUndang Nomor 19 Tahun 2002 yang berlaku efektif mulai tanggal 23 Juli 2003. Sesuai perundang-undangan ini, maka perpustakaan digital harus membatasi akses jaringan komputer dan perangkat lunak ketika pengguna mengakses buku digital supaya tidak menimbulkan permasalahan terkait HAKI, contohnya menggandakan atau mencetak buku digital.

Pustakawan harus memahami beberapa pasal mengenai masalah pidana, yaitu penggandaan koleksi buku dalam menambah jumlah eksemplarnya. Apabila 
merujuk aturan mengenai HAKI, tuntutan pidana dapat dihindari ketika ada royalti yang harus dibayarkan ke penerbit atau pengarang buku sesuai perjanjian yang berlaku antar penerbit dan pengarangnya. Buku yang bersifat fisik atau cetak bersumber dari buku yang dibuat secara digital menggunakan perangkat lunak (software) pengolah kata yang kemudian dicetak atau disimpan ke digital. Biasanya, buku di perpustakaan digital berawal dari buku tercetak pada kertas yang memiliki HAKI (Hidayah, 2017). Buku berbentuk digital pun dapat dibaca menggunakan alat berupa Personal Computer (PC) atau telepon pintar (smartphone).

Perpustakaan digital dalam melakukan penggandaan (copyright) harus sesuai peraturan yang ada agar tidak merugikan penerbit dan pengarang. Peneliti berikan contoh, ketika kita membeli sebuah buku maka kita membeli dan memiliki buku tersebut secara bentuk fisik namun pengarang buku tetap memiliki HAKI atas karangan buku tersebut. Walaupun demikian, ada beberapa pengarang yang menjual buku secara fisik dan HAKI sepenuhnya kepada penerbit. Penulis yang masih memiliki HAKI atas karyanya tersebut pun berlaku untuk buku berjenis elektronik (electronic book). Electronic book (e-book) memiliki hak dan kewajiban yang sama dengan buku versi cetak sehingga $e$-book memiliki harga beli sebagaimana yang dimiliki buku cetak (Sembiring, 2013).

Pengguna perpustakaan sebagai pembaca $e$-book hanya memiliki secara fisik dokumen. Selain itu, pengguna pun bebas membaca menggunakan pelbagai peralatan tetapi tidak memiliki hak untuk mencetak dan menggandakan. Meskipun demikian, e-book dalam perpustakaan digital memiliki fungsi yang sama dengan buku cetak di perpustakaan konvensional yaitu untuk dibaca dan pinjam kembali.

Perpustakaan digital harus bersikap waspada ketika meminjamkan buku. Jika peminjam menggandakan buku yang dipinjam maka ada kasus hukum tersendiri. Maka untuk menghindari hal ini, beberapa perpustakaan digital tidak menyediakan layanan sirkulasi (peminjaman dan pengembalian) koleksi $e$ book walau buku tersebut dimiliki perpustakaan dengan cara dibeli secara sah. Buku cetak dan e-book di perpustakan konvensional dan perpustakaan digital harus sesuai perundang-undangan HAKI, yakni koleksi hanya dapat dipinjam dan dikembalikan saja. Koleksi tidak boleh digandakan dengan cara yang tidak sah atau tanpa izin dari penerbitnya. Maka perpustakaan digital dapat membuat jaringan komputer sendiri atau khusus dalam melayankan koleksi di perpustakaan dan membuat perangkat lunak sebagai media layanan membaca. Hal ini langkah awal dalam membangun perpustakaan digital tanpa melanggar peraturan dan perundang-undangan yang berlaku.

Perpustakaan digital dalam membangun jaringan komputer membutuhkan sumber daya keuangan yang tidak sedikit. Bagi perguruan tinggi yang memiliki ketersediaan sumber daya keuangan baik maka hal ini adalah pilihan tepat sedangkan perguruan tinggi yang memiliki sumber daya keuangan terbatas maka harus dilakukan efisiensi dalam pembangunan perpustakaan digital.

Salah satunya ialah perpustakaan digital di STTA Yogyakarta yang dibangun mulai 2018. Perguruan tinggi dalam memulai proses pembangunan, menyiapkan infrastruktur Teknologi Informasi (TI) yang nantinya dapat 
menghadirkan rasa aman dan legal sesuai peraturan dan perundang-undangan yang berlaku. Untuk itu, Perpustakaan STTA memerlukan infrastruktur jaringan komputer dalam bentuk LAN. Perpustakaan ini telah memiki jaringan LAN sejak 2007 yang digunakan untuk memberikan pelayanan peminjaman, pengembalian buku cetak, dan akses internet kepada para anggota perpustakaan. Jaringan LAN yang ada saat ini masih tergolong LAN tradisional sehingga dibutuhkan beberapa perubahan agar dapat mendukung perpustakaan digital nantinya. Jaringan LAN yang dibangun dan digunakan akan dipecah secara virtual dalam bentuk VLAN sehingga dapat menghadirkan rasa aman (Wicaksono \& Setiawan, 2019).

Jaringan Virtual Local Area Network (VLAN) dalam mendukung pelayanan peminjaman pengembalian koleksi dan katalog terpisah dengan VLAN di perpustakaan digital. Jaringan ini secara fisik menjadi satu tetapi secara non fisik terpisah. Kedua VLAN dapat dihubungkan dengan beberapa ketentuan dan aturan menggunakan inter-VLAN (Pratama, Wintolo, \& Astuti, 2013). Pemilihan jaringan VLAN sebagai teknologi pendukung pada pembangunan perpustakaan digital lebih diutamakan daripada menggunakan jaringan intranet. Jaringan VLAN dapat diisi secara virtual jaringan komputer LAN yang digunakan dalam jumlah lebih dari satu meskipun peralatan jaringan komputer atau switch berjumlah hanya satu buah.

Perpustakaan digital yang dibangun menggunakan jaringan VLAN belum pernah dilakukan sebelumnya sehingga perlu diadakan pengujian dengan harapan memiliki kelebihan dibandingkan perpustakaan digital yang tidak menggunakan jaringan VLAN. Perpustakaan yang sudah membagi jaringan dalam bentuk jaringan VLAN akan menghemat biaya ketika membuat jaringan komputer baru. Sesuai tinjauan literatur terdahulu, penelitian yang meneliti mengenai penerapan jaringan VLAN di perpustakaan digital belum banyak dilakukan dan ditulis pada jurnal nasional di Indonesia. Dengan demikian, penelitian ini mencoba menganalisis mengenai pembagian jaringan komputer menggunakan Virtual Local Area Network (VLAN) guna mendukung perpustakaan digital.

\section{METODE PENELITIAN}

Peneliti dalam penelitian ini menggunakan metode penelitian kualitatif melalui Prepare Plan Design Implement Operate and Optimize (PPDIO). Hal ini disebabkan adanya peralatan cisco switch yang digunakan dalam penelitian ini. Metode penelitian kualitatif membantu peneliti dalam menjelaskan, mendeskripsikan fungsi dan peran peralatan jaringan komputer yang digunakan dalam perancangan. Selain itu, metode penelitian ini pun membantu mempertajam analisis terhadap implementasi hasil rancangan yang diharapkan dapat membawa manfaat bagi pustakawan yang akan mengembangkan perpustakaan ke arah perpustakaan digital.

Tahapan persiapan (prepare) dalam penelitian ini menyiapkan semua kebutuhan perangkat keras dan perangkat lunak yang digunakan dalam membangun perpustakaan digital. Setelah persiapan, selanjutnya penerapan (plan) jaringan komputer VLAN menggunakan alat bantu simulasi perancangan jaringan komputer yaitu packet tracer. Perangkat lunak 
simulator packet tracer yang digunakan sesuai rencana pembelian peralatan, yakni alat ini harus memiliki brand yang dibuat perusahaan yang sama dengan simulatornya. Adapun rancangan jumlah komputer yang akan digunakan harus sama dengan jumlah komputer yang ada. Alamat Internet Protocol Versi 4 (IPV4) menggunakan alamat private 192.168.1.0/24 dan dilakukan konfigurasi pada semua komputer saat perancangannya. Semua komputer yang terancang dapat terhubung ke sebuah switch dan ada dua kabel yang keluar dari switch untuk disambungkan ke jaringan internet dan server dari perpustakaan digital.

Proses

perancangan (design) perpustakaan digital yang selesai dirancang menggunakan packet tracer maka selanjutnya jaringan diuji menggunakan mekanisme pengecekan sinyal dalam jaringan komputer yaitu ping. Apabila jaringan yang diuji menghasilkan sinyal reply maka selanjutnya dilakukan rancangan untuk VLAN yang nantinya digunakan. Setelah komputer memunculkan Request Time Out (RTO) berarti secara fisik komputer yang dituju tidak memiliki sambungan atau hubungan. Berbeda jika komputer memunculkan destination unreachable maka komputer tujuan memiliki sambungan fisik namun secara logical tidak terhubung. Untuk itu, perpustakaan dalam membuat rancangan VLAN harus menggunakan switch pada packet tracer melalui perintah berbasis common line.

Jaringan VLAN memiliki 2 buah yang dapat dilakukan konfigurasi. Satu jaringan VLAN digunakan untuk memberikan pelayanan internet, pelayanan peminjaman, dan pengembalian buku cetak melalui aplikasi SLiMS sedangkan layanan dalam VLAN yang berbeda digunakan untuk perpustakaan digital. Komputer di perpustakaan berjumlah 7 komputer yang dapat dihubungkan ke VLAN pertama, satu komputer terhubung ke VLAN kedua, dan satu buah server terhubung ke VLAN kedua. Selanjutnya, perpustakaan melakukan pengujian hasil perancangan tersebut.

Semua komputer pada satu VLAN diuji dengan perintah ping dan hasilnya memunculkan perintah reply. Kemudian komputer dalam satu VLAN diuji ke komputer yang terhubung VLAN lainnya menggunakan ping dan hasilnya memunculkan RTO. Hal ini menandakan bahwa komputer yang terhubung jaringan VLAN berbeda dan tidak saling terhubung. Maka perpustakaan untuk menghubungkan antar VLAN yang ada membutuhkan peralatan tambahan, yaitu router untuk membangun inter-VLAN. Akan tetapi dalam penelitian ini, jaringan VLAN di perpustakaan sengaja tidak dihubungkan agar tercipta sebuah kondisi layanan perpustakaan digital yang terpisah dari layanan lainnya.

Lebih jelasnya, hasil rancangan jaringan menggunakan packet tracer dapat dilihat pada gambar 1. Komputer yang khusus digunakan untuk pelayanan perpustakaan digital tidak terhubung dengan komputer yang khusus digunakan dalam pelayanan internet dan aplikasi SLiMS melalui simulasi packet tracer. Hal ini dilakukan agar kekuatan masingmasing komputer tidak terganggu dan implementasi penggunaannya akan menghasilkan hasil yang sama. Setelah tahapan perancangan ini berhasil dibuat, jaringan komputer pada perpustakaan STTA kemudian diuji menggunakan ping dari satu komputer ke komputer lain, dari satu jaringan VLAN ke VLAN yang lain. 
Tahap pengujian selesai, peneliti lalu menyusun laporan penelitian dengan harapan hasil penelitian ini dapat dimanfaatkan oleh perpustakaan lain yang ingin membuat perpustakaan digital dan bagi STTA sebagai rekomendasi penelitian selanjutnya terkait pembangunan aplikasi perpustakaan digital berbasis website.

\section{HASIL DAN PEMBAHASAN}

Kondisi awal Perpustakaan STTA dalam menggunakan jaringan komputer terlihat pada gambar 1. Kondisi ini memperlihatkan bahwa belum ada peralatan switch manageable yang mampu digunakan untuk membuat jaringan VLAN seperti terlihat pada gambar 2 .

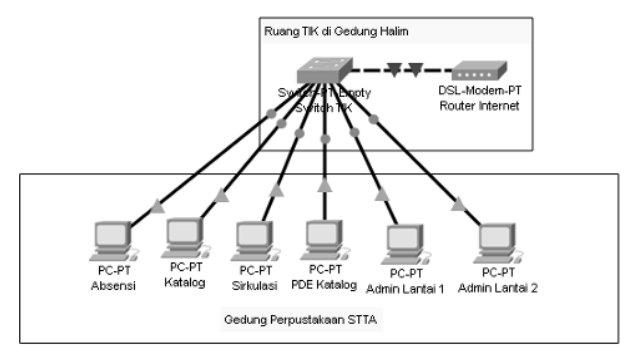

Gambar 1. Kondisi awal jaringan komputer di Perpustakaan STTA Sumber: STTA, 2019

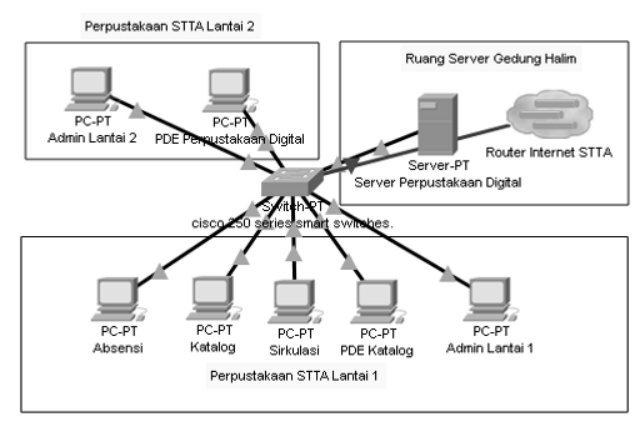

Gambar 2. Rancangan VLAN untuk perpustakaan digital STTA Sumber: STTA, 2019

Langkah selanjutnya dalam penelitian ini adalah implement untuk semua rancangan yang telah dilakukan. Hal yang mengalami perubahan yaitu kabel yang digunakan dalam pelayanan perpustakaan STTA yang konvensional diganti menggunakan kabel LAN yang baru dengan kualitas yang lebih baik. Hal ini dilakukan agar kecepatan akses jaringan komputer menjadi lebih baik dan cepat dibandingkan dengan yang lama. Peralatan jaringan komputer berupa switch yang tidak manageable digantikan dengan switch yang manageable. Dana yang dibutuhkan sebesar 8 juta rupiah untuk mengubah infrastruktur kabel jaringan komputer untuk 13 titik sambungan dengan total panjang kabel yang dibutuhkan 200 meter dan kabel yang digunakan Unshielded Twisted Pair (UTP) kategori 6. Kabel LAN di perpustakaan yang lama merupakan kabel UTP dengan kategori 3. Salah satu pertimbangan mengganti kabel lama dengan kabel baru karena dukungan teknologi perpindahan data pada kabel kategori 6 lebih cepat dibandingan dengan kabel lama yang masih menggunakan kategori 3.

Perbedaan kategori ini disebabkan pemakaian teknologi ethernet card yang ada pada peralatan komputer, switch, dan router. Kecepatan yang didukung ethernet card menggunakan kabel UTP ini bisa mencapai 100 mega bit per detik bahkan ada yang mampu hingga 1 giga bit per detik. Tingginya kecepatan perpindahan data sangat mendukung terhadap upaya pembuatan perpustakaan digital karena ukuran dokumen e-book yang cukup besar.

Perpustakaan digital sangat membutuhkan teknologi yang cepat dalam pemindahan data agar pengguna dapat menekan waktu yang dibutuhkan untuk mencari dan membaca e-book dalam waktu di bawah 10 detik, seperti kabel UTP, ethernet card, dan prosesor komputer. Prosesor dan memori komputer server di mana perangkat lunak perpustakaan digital dipasangkan membantu 
perpustakaan dalam mengakses e-book secara cepat, menarik cepat jumlah anggota perpustakaan saat akses perpustakaan digital yang melewati peralatan jaringan komputer switch.

Pada gambar 2 terlihat rancangan VLAN dengan komposisi 7 komputer berupa Personal Computer (PC) yang digunakan pustakawan dan pengunjung perpustakaan STTA dan 1 komputer tempat mengakses layanan perpustakaan digital dan satu buah server untuk perpustakaan digital STTA. Sesuai data dari 7 PC, 6 buah hanya diperbolehkan untuk dioperasikan pustakawan dan tenaga kependidikan bidang TI dan 1 buah boleh digunakan pengunjung perpustakaan, yaitu komputer pencarian data katalog. Adapun server dan router yang terhubung ke jaringan internet terletak di gedung yang berbeda dari Perpustakaan STTA. Ruangan ini berupa server room STTA di Gedung Halim. Adapun untuk layanan akses internet terdapat jaringan komputer sendiri yang dikelola bagian Unit Pelayanan Teknis Teknologi Informasi dan Komputer (UPT TIK) STTA melalui peralatan jaringan komputer bernama Wireless Access Point (WAP) sebanyak 4 buah yang dapat dimanfaatkan pengunjung perpustakaan.

Gedung Perpustakaan STTA berlantai dua. Di mana pada lantai satu terdapat komputer untuk pengisian daftar hadir pengunjung perpustakaan yang diletakkan depan pintu masuk dan komputer katalog elektronik yang digunakan untuk akses data buku cetak. Komputer katalog elektronik khusus digunakan untuk kegiatan sirkulasi perpustakaan misalnya pelayanan peminjaman dan pengembalian buku cetak oleh anggota Perpustakaan STTA. Di mana buku-buku yang diletakkan di rak buku lantai satu merupakan koleksi yang khusus dipinjamkan sedangkan buku yang berada di lantai dua merupakan buku cetak yang hanya dapat dibaca di ruang baca Perpustakaan.

Adapun komputer Pengolahan Data Elektronik (PDE) khusus katalog digunakan pustakawan di bagian layanan teknis untuk menunjang pekerjaan dalam melakukan pencatatan elektronis buku cetak koleksi Perpustakaan STTA. Komputer selanjutnya yang berada di lantai satu adalah komputer administrasi yang digunakan untuk memberikan pelayanan surat menyurat yang dibutuhkan Mahasiswa STTA. Kemudian komputer PDE perpustakaan digital yang digunakan untuk memasukan data buku digital rencananya akan dibangun berbasis website. Komputer ini nantinya dapat digunakan untuk akses perpustakaan digital bagi pengunjung perpustakaan yang tidak memiliki komputer. Selain itu, pengunjung yang membawa komputer jinjing pun dapat mengakses perpustakaan digital melalui WAP perpustakaan digital yang diletakan di lantai dua. Lalu ada 4 buah komputer yang disediakan sebagai layanan referensi yang terhubung jurnal elektronik berbayar atau berasal dari penerbit EBSCO dan dapat digunakan bagi pengunjung yang tidak membawa komputer jinjing ketika mengakses internet.

Komputer yang memiliki fungsi sebagai server dari perpustakaan digital diletakkan pada gedung yang berbeda dan di bawah tanggung jawab UPT TIK STTA. Demikian router yang digunakan untuk memberikan layanan akses internet bagi pengunjung Perpustakaan STTA diletakkan satu tempat dengan server perpustakaan digital STTA. Masingmasing komputer yang terletak pada 
lantai serta gedung yang berbeda diberi alamat Internet Protocol (IP) pada alamat jaringan yang sama yaitu 192.168.1.0/24. Artinya masing-masing komputer yang ada diberikan alamat 192.168.1.1 hingga 192.168.1.12 dengan subnet mask yang diisikan pada semua komputer yaitu 255.255.255.0.

Setelah pemberian alamat IP pada gambar 2 selesai dilakukan, langkah selanjutnya yaitu melakukan operate pada jaringan perpustakaan digital ini untuk dilakukan pengetesan koneksi data dari satu PC ke PC lain dan ke server secara bergantian menggunakan perintah ping, seperti terlihat pada gambar 2. Proses ping muncul maka waktu perpindahan data yang dapat dilihat pada gambar 2. Hal ini menunjukkan bahwa kecepatan perpindahan data e-book pada perpustakaan belum dapat ditentukan dari ping yang digunakan karena tergantung ukuran paket data yang digunakan.

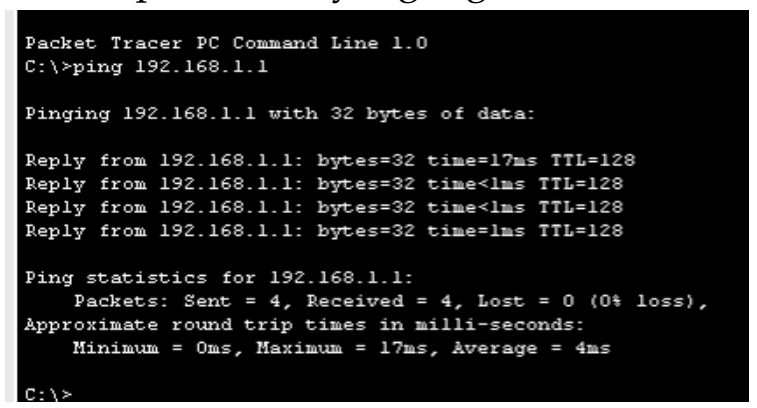

Gambar 3. Hasil pengujian menggunakan Ping Sumber: STTA, 2019

Pada gambar 3, pengujian dilakukan saling bergantian dari PC ke PC lain hingga ke server. Kemudian hasil data disusun dalam sebuah tabel hasil pengujian seperti terlihat pada tabel 1 . Hal ini dilakukan untuk memastikan bahwa secara fisik semua komputer yang ada telah tersambung dengan baik dan tidak mengalami gangguan sinyal saat dilewati paket data.
Salah satu hasil pengujian menggunakan ping adalah reply. Kata reply pada tabel 1 memiliki arti bahwa antara komputer telah tersambung secara physical dan logical melalui kabel serta memiliki alamat jaringan yang sama yaitu 192.168.0.0. Semua kabel yang digunakan dalam implementasi jaringan komputer yang digunakan untuk perpustakaan digital STTA telah tersambung dengan baik dan tidak ada permasalahan dalam sinyal komunikasi data. Maka data anggota perpustakaan, data katalog, data e-book, data lain pada sistem yang ada, dan sistem yang akan dibangun dapat tersambung sesuai tujuan penelitian.

Tabel 1

\begin{tabular}{lll}
\multicolumn{2}{l}{ Hasil Pengujian Ping } & \\
\hline No & Nama PC & $\begin{array}{l}\text { Hasil Test } \\
\text { Ping }\end{array}$ \\
\hline 1 & PC absensi & Reply \\
2 & PC katalog & Reply \\
3 & PC sirkulasi & Reply \\
4 & PC PDE katalog & Reply \\
5 & PC admin lantai 1 & Reply \\
6 & PC admin lantai 2 & Reply \\
7 & Referensi 1 & Reply \\
8 & Referensi 2 & Reply \\
9 & Referensi 3 & Reply \\
10 & Referensi 4 & Reply \\
11 & PC PDE perpustakaan & Reply \\
& digital & \\
12 & Server & Reply \\
13 & Router internet STTA & Reply \\
\hline
\end{tabular}

Sumber: STTA, 2019

Langkah berikutnya yaitu melakukan optimize melalui proses konfigurasi ulang alamat IP berdasarkan pembagian alamat IP yang diberikan bagian UPT TIK STTA yang kemudian dipasangkan pada semua komputer di perpustakaan. Hal ini 
dilakukan agar semua komputer di Perpustakaan STTA tersambung ke jaringan internet dan dapat digunakan untuk mengakses pelayanan di perpustakaan yaitu perangkat lunak SLiMS. Alamat IP 110.168.3.49 hingga 110.168.3.54 digunakan untuk komputer daftar hadir, katalog, sirkulasi, PDE, katalog, admin 1, dan admin 2. Serta alamat IP 110.168.1.2.22 hingga 110.168.2.25 digunakan untuk komputer referensi sebanyak 4 buah yang berada di lantai 2 Perpustakaan STTA. Alamat IP yang lainnya dikonfigurasikan ke komputer yang digunakan untuk memberikan pelayanan perpustakaan digital yaitu 172.168.0.1 dan 172.168.0.2.

\section{Tabel 2}

Pemberian alamat IP dan pengujian konektivitas ke internet

\begin{tabular}{llll}
\hline No & Nama & Alamat IP & $\begin{array}{l}\text { Hasil test } \\
\text { ping }\end{array}$ \\
\hline 1. & Absensi & 110.168 .3 .52 & Reply \\
2. & Katalog & 110.168 .3 .53 & Reply \\
3. & Sirkulasi & 110.168 .3 .51 & Reply \\
4. & PDE Katalog & 110.168 .3 .54 & Reply \\
5. & Admin 1 & 110.168 .3 .49 & Reply \\
6. & Admin 2 & 110.168 .3 .50 & Reply \\
7. & Admin & 172.168 .0 .2 & Request \\
& perpustakaan & & Time out \\
& digital & & \\
8. & Referensi 1 & 110.168 .2 .22 & Reply \\
9. & Referensi 2 & 110.168 .2 .23 & Reply \\
10. & Referensi 3 & 110.168 .2 .24 & Reply \\
11. & Referensi 4 & 110.168 .2 .25 & Reply \\
12. & Server & 172.168 .0 .1 & Request \\
& perpustakaan & & Time out \\
& digital & & \\
\hline
\end{tabular}

Sumber: STTA, 2019

Setelah konfigurasi selesai kemudian dilakukan pengujian menggunakan ping ke google.com sebagai representasi dari jaringan internet dengan hasil yang dapat dibaca pada tabel 2. Ping tidak diarahkan ke perangkat lunak SLiMS yang digunakan pada alamat http://perpustakaan.stta.ac.id/ karena hasilnya akan terjadi RTO. Hal ini dilakukan untuk menghindari serangan ping of death ke server SLiMS dengan melakukan konfigurasi pada firewall server tersebut. Jika server SLiMS terkena serangan hecker dan server melayani ping terus menerus maka mekanisme ping akan menyebabkan pelayanan perpustakaan pada perangkat lunak terganggu sehingga server tidak bisa digunakan lagi untuk pelayanan Perpustakaan STTA.

Komputer dengan nama absensi digunakan untuk merekam data pengunjung Perpustakaan STTA yang perangkat lunaknya terpasang di komputer server STTA. Nama alamat IP absensi ditulis di belakang nama domain stta.name dan perpustakaan dapat mengakses melalui jaringan internet yang telah dibuat pada LAN seperti terlihat di tabel 2. Pelayanan perekaman daftar hadir sangat bermanfaat untuk merekam data pengunjung perpustakaan yang terlihat pada gambar 3. Perangkat lunak untuk pengisian daftar hadir pengunjung Perpustakaan STTA dibuat bagian UPT TIK STTA yang digunakan untuk merekam data pengunjung. Data rekam pengunjung perpustakaan ini nantinya dibandingkan dengan data peminjaman buku pada perangkat lunak SLiMS untuk membuat analisis terkait motivasi kunjungan mahasiswa ke Perpustakaan STTA.

Komputer katalog, sirkulasi, dan PDE katalog terhubung ke jaringan internet. Anggota perpustakaan dapat mengakses $e$ book menggunakan perangkat lunak SLiMS. Komputer katalog akan menampilkan hasil pencarian data buku 
cetak sebagai koleksi Perpustakaan STTA. Anggota perpustakaan pun menggunakan komputer bagian sirkulasi dalam mengakses SLiMS melalui jaringan internet. Setelah perangkat lunak SLiMS dapat diakses selanjutnya petugas harus login menggunakan username dan password untuk mencatat sirkulasi dan mencatat inventaris buku cetak yang baru masuk ke Perpustakaan STTA.

Adapun pengunjung perpustakaan yang ingin mengakses katalog dapat menggunakan perangkat lunak SLiMS agar tidak perlu datang secara fisik ke Perpustakaan STTA melalui komputer yang terakses internet. Pengguna dapat mencari informasi koleksi secara detail dan mengakses buku cetak melalui kunjungan ke alamat http:/ / perpustakaan.stta.ac.id/. Selain itu, komputer admin 1 dan admin 2 terhubung ke internet dalam memberikan layanan surat menyurat bagi anggota perpustakaan. Alamat IP komputer yang didapatkan dari bagian UPT TIK STTA dapat digunakan juga komputer yang terhubung ke jaringan internet dan sebelumnya telah berhasil dilakukan tes pengujian menggunakan ping dengan hasil reply.

Pada nomor 7 dan 12 di tabel 2, hasil pengujian konektivitas jaringan internet menggunakan perintah ping didapatkan hasil bahwa kedua nomor time out, tidak seperti nomor lain yaitu reply. Hal ini terjadi karena pada alamat IP yang digunakan komputer pada nomor 7 dan 12 tidak dihubungkan ke jaringan internet melalui router STTA sedangkan alamat yang lain dihubungkan menggunakan teknik routing. Akan tetapi, cara pemberian alamat IP pada komputer ini dapat dilakukan semua orang yang paham dalam operasional komputer sehingga alamat IP dengan mudah dapat diganti.

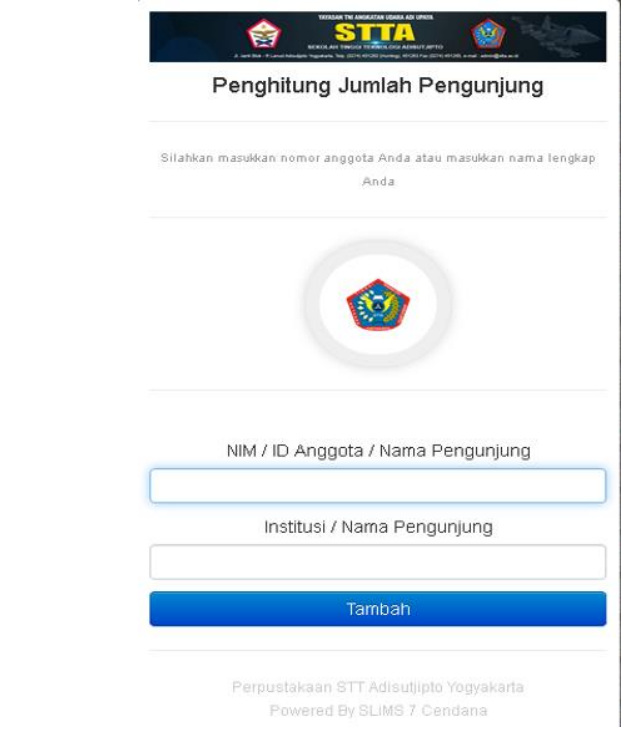

Gambar 4. Tampilan perangkat lunak (software) absensi pengunjung perpustakaan Sumber: STTA, 2019

Berdasarkan alamat IP yang mudah diubah ini, maka petugas akan mudah menghubungkan jaringan internet atau malah memutuskan jaringan satu komputer dengan komputer lain. Hal ini akan menimbulkan masalah keamanan bagi komputer dan jaringan pun rentan untuk disusupi.,Untuk itu, langkah selanjutnya adalah mengamankan jaringan komputer dengan membuat jaringan VLAN pada cisco 250 series smart switches yang digunakan sebagai alat penghubung semua komputer. Namun tidak semua peralatan jaringan komputer yang bernama switch mampu digunakan untuk membuat VLAN. Maka penelitian ini menggunakan jaringan komputer switch seri 250 sebagai produk dari Cisco Switch yang manageable yang dapat digunakan dengan mudah untuk membuat VLAN.

Ketika membuat jaringan VLAN sangat mudah diikuti bahkan orang yang tidak memiliki kemampuan bidang network engineer pun dapat melakukannya. Hal yang perlu dilakukan adalah 
membaca manual book dari peralatan tersebut dan mengikuti apa yang sudah tertulis di sana. Semua konfigurasi dan pembuatan VLAN dilakukan dengan aplikasi berbasis website sehingga anggota perpustakaan dapat mengakses menggunakan komputer yang terhubung ke switch dengan alamat IP sesuai tertulis pada manual book.

Setelah nomor dan nama jaringan VLAN dibuat maka konfigurasi port ethernet yang tersambung ke setiap komputer di bagian atau anggota VLAN yang telah dibuat. Port ethernet pada switch yang digunakan sebaiknya dimasukan dalam jaringan VLAN agar tidak digunakan oleh orang lain yang tidak memilki hak dan kepentingan. Apabila ada kegagalan (default) dalam sebuah switch manageable, misalnya hanya ada satu jaringan VLAN maka akan menimbulkan masalah flooding pada switch.

Ciri munculnya masalah flooding ialah lampu indikator setiap ethernet menyala dan mati secara bergantian secara terus menerus. Maka jaringan VLAN yang dibuat dalam peralatan jaringan komputer switch harus minimal 2 buah untuk mencegah terjadinya flooding. Hal ini berarti bahwa jaringan VLAN yang digunakan untuk membagi jaringan pada perpustakaan digital mampu digunakan sebagai awal membangun keamanan bagi server perpustakaan digital.

Pada tabel 3, jaringan VLAN dibagi menjadi dua jaringan VLAN. Jaringan pertama, komputer yang berada dalam VLAN 1 bernama VLAN Perpustakaan Digital tidak akan dapat mengakses komputer VLAN 2. Jaringan kedua, komputer yang berada dalam VLAN 2 bernama VLAN Internet dan SLiMS pun tidak akan bisa mengakses VLAN 1. Maka terlihat bahwa jika jaringan semua alamat
IP pada komputer disamakan menggunakan IP 110.168.3.0/24, hasil ping antar komputer pada jaringan VLAN yang berbeda akan memunculkan RTO.

Tabel 3

VLAN dan anggotanya

\begin{tabular}{|c|c|c|}
\hline No & Nama VLAN & Anggota \\
\hline 1 & $\begin{array}{l}\text { Perpustakaan } \\
\text { digital }\end{array}$ & $\begin{array}{l}\text { - Admin perpustakaan } \\
\text { digital } \\
\text { - Server perpustakaan } \\
\text { digital } \\
\text { - Wireless access point } \\
\text { (elibrary) }\end{array}$ \\
\hline 2 & $\begin{array}{l}\text { Internet dan } \\
\text { SLiMS }\end{array}$ & $\begin{array}{l}\text { - Absensi } \\
\text { - Katalog } \\
\text { - Sirkulasi } \\
\text { - PDE Katalog } \\
\text { - Admin } 1 \\
\text { - Admin } 2 \\
\text { - Referensi } 1 \\
\text { - Referensi } 2 \\
\text { - Referensi } 3 \\
\text { - Referensi } 4\end{array}$ \\
\hline
\end{tabular}

Sumber: STTA, 2019

Demikian juga akses komputer yang dilakukan orang lain melalui jaringan internet pada VLAN 2, tidak akan mampu masuk dan mengakses komputer pada VLAN 1 yang salah satunya berupa website server Perpustakaan Digital STTA. Pada jaringan VLAN perpustakaan digital ada satu peralatan yang ditambahkan, bernama WAP. Peralatan ini disediakan untuk memberikan layanan akses nirkabel bagi mahasiswa yang ingin mengakses Perpustakaan Digital STTA menggunakan peralatan komputer jinjing milik sendiri.

Komputer dalam penggunaan jaringan VLAN dapat diubah dengan mudah susunan di perpustakaan apabila terdapat kebijakan manajerial yang menghendaki susunan keanggotaan komputer pada jaringan ini. Adapun proses perubahan tidak mengganggu 
komunikasi data komputer lain pada jaringan VLAN yang ada. Maka baiknya komputer yang akan diubah keanggotaan dalam sebuah VLAN tidak digunakan. Proses perubahan hanya membutuhkan waktu dalam hitungan detik dengan menggunakan aplikasi yang sama saat membuat jaringan VLAN dan mendaftarkan anggota VLAN.

Pengelompokan pelayanan dari komputer server yang di dalamnya ada perangkat lunak untuk mendukung kinerja perpustakaan berdasarkan letaknya dapat dilihat pada tabel 4. Sesuai tabel 4, VLAN 1 merupakan VLAN Perpustakaan Digital STTA sedangkan VLAN 2 merupakan VLAN Internet dan Senayan.

Tabel 4

Layanan perangkat lunak pada Perpustakaan STTA

\begin{tabular}{|c|c|c|c|}
\hline \multirow[t]{2}{*}{ No } & \multirow{2}{*}{$\begin{array}{l}\text { Nama } \\
\text { perangkat } \\
\text { lunak }\end{array}$} & \multicolumn{2}{|c|}{ Akses komputer dari } \\
\hline & & VLAN 1 & VLAN2 \\
\hline 1 & SLiMS & $\mathrm{X}$ & $\checkmark$ \\
\hline 2 & $\begin{array}{l}\text { Referensi } \\
\text { (EBSCO) }\end{array}$ & $\mathrm{X}$ & $\checkmark$ \\
\hline 3 & $\begin{array}{l}\text { Absensi } \\
\text { Pengunjung }\end{array}$ & $\mathrm{X}$ & $\checkmark$ \\
\hline 4 & Katalog & $\mathrm{X}$ & $\checkmark$ \\
\hline 5 & Internet & $\mathrm{X}$ & $\checkmark$ \\
\hline 6 & Eprint & $\mathrm{X}$ & $\checkmark$ \\
\hline 7 & Elibrary & $\checkmark$ & $\mathrm{X}$ \\
\hline & $\begin{array}{l}\text { angan: } \\
\text { X = Tidak te } \\
\checkmark=\text { Terhub }\end{array}$ & ing & \\
\hline
\end{tabular}

Sumber: STTA, 2019

Pengujian selanjutnya terhadap implementasi rancangan jaringan komputer VLAN untuk mendukung perpustakaan digital di Perpustakaan STTA, yaitu mengakses semua pelayanan Perpustakaan STTA melalui komputer yang sudah menjadi anggota pada jaringan
VLAN 1 dan VLAN 2. Hasil pengujian ini dapat dilihat pada tabel 4. Perpustakaan dapat melakukan uji beberapa perangkat lunak dan melakukan akses pada SLiMS, EBSCO, absensi pengunjung, katalog, internet, EPrints, dan electronic library (elibrary).

Hasil pengujian pada tabel 4 dilakukan dengan cara mengakses perangkat lunak yang digunakan untuk pelayanan peminjaman dan kembali menggunakan SLiMS. Kemudian pelayanan referensi diuji dengan membuka halaman EBSCO dan eprint yang beralamatkan di http://eprints.stta.ac.id/, menggunakan komputer bagian layanan referensi. Adapun komputer yang digunakan untuk mengisi daftar hadir pengunjung Perpustakaan STTA diuji dengan mengakses pelayanan absensi pengunjung. Komputer yang digunakan untuk katalog diuji dengan cara membuka perangkat lunak SLiMS di mana pada halaman utamanya tersaji menu pencarian buku. Kemudian internet pada tabel 4 dimaksudkan sebagai sambungan koneksi internet yang untuk akses semua komputer pada jaringan VLAN 2 yang lalu diuji dengan membuka perangkat lunak SLiMS.

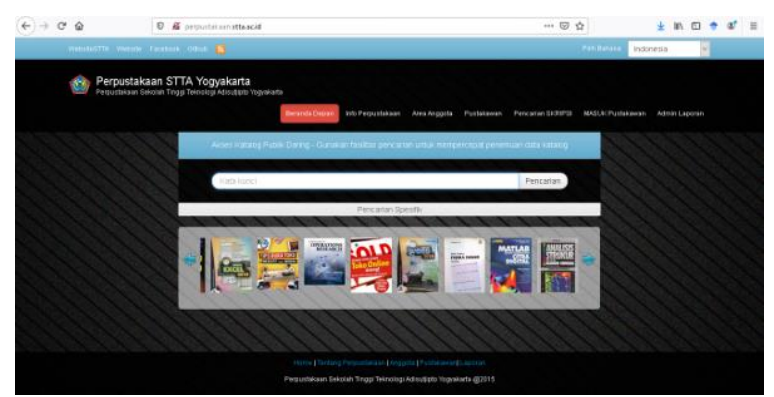

Gambar 4. Perangkat lunak SLiMS yang diakses melalui jaringan internet Sumber: STTA, 2019

Semua perangkat lunak dapat dilakukan akses menggunakan komputer yang tersambung pada jaringan VLAN 2 kecuali elibrary. Pada dasarnya semua 
komputer anggota dari jaringan VLAN 1 dapat digunakan untuk mengakses semua sumber daya yang ada. Komputer jaringan VLAN 1 dikhususkan untuk memberikan pelayanan sesuai nama PC pada tabel 1 agar pelayanan dan administrasi tertib.

Perangkat lunak elibrary di Perpustakaan STTA dalam tahap perencanaan dan penelitian selanjutnya akan dilakukan. Meskipun demikian, infrastruktur jaringan komputer telah dihasilkan dari rangkaian penelitian ini sehingga dapat dimanfaatkan untuk perpustakaan digital nantinya. Sesuai lokalisasi elibrary pada jaringan VLAN 1 seperti terlihat pada tabel 4, akses terhadap layanan buku digital di Perpustakaan Digital STTA lebih aman dan legalitas lebih terjamin karena buku digital hanya dapat dibaca di Perpustakaan STTA.

Semua komputer yang tidak terdaftar pada jaringan VLAN 1 tidak akan dapat mengakses pelayanan Perpustakaan Digital STTA. Dengan demikian, alur akses membaca buku digital dapat dikendalikan dan diatur baik sehingga dapat mencegah pelanggaran hak cipta dari e-book yang sebagai koleksi Perpustakaan Digital STTA.

\section{Perpustakaan}

dengan

mempersiapkan perangkat keras dan jaringan komputer maka dapat mendukung operasional pelayanan perpustakaan digital yang mematuhi aturan HAKI. Untuk itu, perpustakaan pun harus memperhatikan pembuatan perangkat lunak dan dapat mengadopsi peraturan dan perundang-undangan yang berlaku. Dengan demikian, pihak perpustakaan digital harus merancang buku digital atau e-book agar dapat dibaca, dipinjam, dan dikembalikan seperti pelayanan peminjaman pengembalian buku cetak.

Perpustakaan digital mencoba melayani pengunjung yang ingin mengakses buku digital secara online. Pengunjung dapat mengakses buku digital tanpa harus hadir secara fisik ke Perpustakaan STTA. Maka perpustakaan pun menambah WAP sesuai jarak bentang kabel maksimum hingga 100 meter ke switch sebagai bagian dari jaringan VLAN 2. Jika jarak lebih dari 100 meter, maka ada dua cara membuat koneksi dari WAP dengan switch di perpustakaan. Pertama, perpustakaan menggunakan switch tambahan hingga ke lokasi yang dituju. Cara ini mengandung risiko yang cukup besar yaitu kestabilan sinyal komunikasi data dan celah keamanan yang terbuka antara switch yang dipasang sebagai penguat sinyal. Kedua, perpustakaan menggunakan fiber optic untuk menghubungkan WAP dengan switch. Cara kedua tidak memiliki resiko seperti halnya cara pertama akan tetapi biaya yang digunakan untuk membangunnya cukup besar.

\section{SIMPULAN}

Berdasarkan hasil pembahasan di atas dapat ditarik kesimpulan bahwa Pembangunan perpustakaan digital di Perpustakaan STTA dapat dilakukan tanpa membangun jaringan komputer sendiri melalui konfigurasi jaringan komputer yang ada dalam 2 buah jaringan VLAN yang memberikan dua layanan yang berbeda. Jaringan VLAN dibuat dengan melakukan konfigurasi pada peralatan jaringan komputer yang memiliki fasilitas dan kemampuan dalam pengelolaan jaringan VLAN melalui switch. Perpustakaan dapat menambah dan mengurangi keanggotaan komputer 
dalam sebuah jaringan VLAN melalui perangkat lunak yang sama dan perangkat lunak yang mudah digunakan dengan manual book dibaca terlebih dahulu. Ada beberapa faktor yang menentukan kecepatan akses e-book di perpustakaan digital, di antaranya faktor jenis kabel yang digunakan dalam membangun jaringan komputer LAN, kecepatan prosesor komputer yang digunakan untuk mengakses, dan memori komputer yang digunakan sebagai server dari perpustakaan digital. Jaringan VLAN yang telah dibuat dapat digunakan untuk mengakses perangkat lunak SLiMS, daftar hadir pengunjung, EBSCO, EPrints, internet, dan elibrary sesuai fungsi pada jaringan VLAN 1 dan VLAN 2. Jaringan VLAN yang dibuat untuk mendukung kinerja perpustakaan digital dan dapat membatasi hak akses anggota perpustakaan ketika mencari buku digital, membaca dengan tidak ada kegiatan pinjam meminjam, dan mencetak buku secara hardcopy atau softcopy. Perpustakaan STTA menggunakan dua cara dalam melayankan e-book. Pertama, anggota perpustakaan dapat mengakses PC yang sudah disediakan perpustakaan. Kedua, anggota perpustakaan dapat juga menggunakan komputer jinjing dan telepon pintar (smartphone) melalui WAP yang telah disediakan perpustakaan dalam mengakses buku digital. Kedua cara ini hanya bisa dilakukan dalam gedung Perpustakaan STTA. Anggota perpustakaan dapat meluaskan akses pelayanan tanpa datang ke perpustakaan. Maka perpustakaan dapat menambah WAP dan menghubungkan switch di perpustakaan menggunakan kabel UTP dengan jarak maksimum 100 meter atau fiber optic yang jarak maksimumnya dapat mencapai $2 \mathrm{~km}$. Untuk itu, perpustakaan dapat memikirkan dan mengkaji perangkat lunak yang akan digunakan dalam mengakses e-book. Perpustakaan pun dapat menempatkan server untuk mengadopsi ketentuan dan peraturan perundang-undangan yang berlaku agar tidak menimbulkan masalah hukum bagi STTA Yogyakarta. Penelitian selanjutnya yang perlu dilakukan yaitu membuat perangkat lunak yang digunakan untuk mengakses layanan perpustakaan digital menggunakan mobile computing yang dilayani akses poin dalam jaringan terbatas.

\section{DAFTAR PUSTAKA}

Dana, T., Samosir, D. H., \& Widiyasa, I. M. (2015). Pengembangan digital library Perpustakaan Universitas Atmajaya Yogyakarta. Seminar Nasional Informatika (SEMNASIF), 260-263. Retrieved from http://jurnal.upnyk.ac.id/index.php /semnasif/article/view/781/661

Hidayah, K. (2017). Hukum Hak Kekayaan Intelektual (HAKI). Malang: Setara Press.

Irkhamiyati. (2017). Evaluasi persiapan Perpustakaan Stikes 'Aisyiyah Yogyakarta dalam membangun perpustakaan digital. Berkala Ilmu Perpustakaan Dan Informasi, 13(1), 3746.

https:/ / doi.org/10.22146/bip.26086

Kusmawan, D. (2014). Perlindungan hak cipta atas buku. Perspektif: Kajian Masalah Hukum Dan Pembangunan, 19(2), 137-143. https:/ / doi.org/10.30742/ perspektif. v19i2.16

Oktaviani, F., Yusup, P., \& Khadijah, U. (2018). Penggunaan layanan open library dalam memenuhi kebutuhan informasi mahasiswa Telkom 
University. Jurnal Kajian Informasi $\mathcal{E}$ Perpustakaan, 5(2), 127-140.

https:// doi.org/10.24198/jkip.v5i2.12 856

Pratama, A. W., Wintolo, H., \& Astuti, Y. (2013). Konfigurasi inter-VLAN pada cisco berbasis Graphics User Interface (GUI) sebagai pembelajaran peralatan jaringan komputer cisco. Compiler, 2(2), 13-20. https://doi.org/10.28989/compiler.v 2i2.207

Putra, I., \& Irawati, I. (2018). Layanan referensi sebagai representasi perpustakaan perguruan tinggi. Jurnal Kajian Informasi \& Perpustakaan, 6(1), 77-94.

https:/ / doi.org/10.24198/jkip.v6i1.13 464

Rodliyah, U. (2012). Perpustakaan digital dan prospeknya menuju resource sharing. Visi Pustaka, 14(1), 39-47. Retrieved from https://www.perpusnas.go.id/maga zine-detail.php?lang=id\&id $=8219$

Sembiring, S. (2013). Aspek-aspek yuridis dalam penerbitan buku. Bandung: Nuansa Aulia.

\section{Retrieved from}

http:/ / repository.unpar.ac.id/bitstre am/handle/123456789/2316/Sentosa _142530p.pdf?sequence=1\&isAllowey Sugianti, S. (2016). Uji ketergunaan layanan antarmuka Magister Management Digital Library (MMDigilib) Perpustakaan Magister Manajemen Fakultas Ekonomi Universitas Indonesia. Berkala Ilmu Perpustakaan Dan Informasi, 10(2), 3339.

https:// doi.org/10.22146/ bip.8833

Sukirno, S. (2015). Evaluasi pemanfaatan koleksi buku digital oleh mahasiswa pendidikan dokter di Unit Perpustakaan Fakultas Kedokteran Universitas Gadjah Mada (FK UGM). Berkala Ilmu Perpustakaan Dan Informasi, 9(2), 8-17.

https:/ / doi.org/10.22146/ bip.7781

Wicaksono, A., \& Setiawan, C., B. (2019). VLAN wireless performance analysis of central access point management topology according to the IEEE 802.11 standard. Compiler, 8(2), 119-130. https:// doi.org/10.28989/compiler.v $8 \mathrm{i} 2.525$ 